\title{
MANAGING DYNAMIC COMPLEXITY: OPPORTUNITIES FOR SYSTEMS THINKING IN GRADUATE MANAGEMENT EDUCATION
}

Vijay R. Kannan (corresponding author)

Department of Business Administration

Utah State University 3510 Old Main Hill

Logan, UT 84322-3510

Phone: (435) 7977212

Fax; (435) 7972634

Email: v.kannan@usu.edu

J. Brian Atwater

Department of Business Administration

Utah State University 3510 Old Main Hill

Logan, UT 84322-3510

Phone: (435) 7973982

Fax; (435) 7972634

Email: brian.atwater@business.usu.edu

Alan A. Stephens

Department of Business Administration

Utah State University 3510 Old Main Hill

Logan, UT 84322-3510

Phone: (435) 7972367

Fax; (435) 7972634

Email: alan.stephens@business.usu.edu 


\title{
MANAGING DYNAMIC COMPLEXITY: OPPORTUNITIES FOR SYSTEMS THINKING IN GRADUATE MANAGEMENT EDUCATION
}

\begin{abstract}
Competition and time pressure to respond are adding to the challenges faced by business leaders. Managers are increasingly faced with decision making scenarios characterized by significant dynamic complexity. While systems thinking tools exist to help prepare managers deal with dynamic complexity, it is not clear whether managers are in fact aware of or incorporating systems thinking in making complex decisions. Results of a survey of faculty at the leading graduate schools of management in the U.S. suggest that opportunities exist to expand the awareness of systems thinking both among faculty and the managers they are preparing. Moreover, they demonstrate a need to distinguish thinking about systems from thinking systemically.
\end{abstract}

Keywords: Systems thinking, Dynamic complexity, Management education 


\section{Decision making: The challenge of dynamic complexity}

The business world continues to grow more complex and dynamic. Product innovations, for example, provide a company with a period of competitive advantage that is decreasing as other organizations respond quickly with their own improvements. Similarly, benchmarking, business partnering, and efforts to integrate decision making across the supply chain, have significantly reduced the length of time that internal process innovations can serve as a source of competitive advantage. These and other factors continue to reduce the amount of time managers have to gather and process information, consider the implications of various alternatives, and make decisions. While this complexity has increased however, there is evidence that the ability of managers to cope with it has not. The press reports regularly about major companies failing to perform as expected. This performance has resulted in high turnover among upper-level executives. The average tenure of new CEO's is now about 18 months (Charan, 2005), while in the year 2000, 40 CEO's of Fortune's top 200 companies were fired or asked to resign (Bossidy \& Charan, 2000). When CEO's fail it inevitably impacts the firms they are running. Change in leadership and management philosophy, as well as the accompanying transition, can not only be disruptive, it can bring changes in strategic as well as tactical direction. In a 2003 white paper, Morris showed that an average of 30 companies drop off the Fortune 500 list every year, and the average life of firms on the S\&P 500 is only 25 years. New businesses are faced with similar challenges. For every successful new business there are 22 failures, and for those that do survive, the average life span is only 11.5 years.

While there are many factors that contribute to poor corporate performance, with roots both internal and external to the organization, the impact of complexity is one that cannot be overlooked. Indeed, in light of the challenges of complexity, competition, and time, it is not 
surprising that poor, sometimes illegal or unethical decisions are made. It is also not surprising that when faced with the challenges of a complex, dynamic environment, decisions are made that reflect a short term, sometimes reactive, perspective rather than creating sustainable long term value. However, despite the many articles published on these issues in both popular and academic journals, an important aspect of the complexity managers must deal with is often overlooked.

Complexity is often viewed in terms of the number of variables that must be considered in making a decision. For example, a situation is considered complex when many different stakeholders must be considered, a variety of objectives are to be achieved, or several resources are used to achieve them. In these situations, there are typically a large number of solutions to achieve a particular objective. This type of complexity is referred to as detail complexity (Sterman, 2000a). Developing methods to help managers deal with detail complexity has been a primary focus of business education and management training for many years. However, addressing only detail complexity often results in predictable failures due to inattention to dynamic complexity (Sterman, 2000a). Dynamic complexity arises from the interaction of variables over time. There are two key aspects of dynamic complexity; time and feedback. How variables behave over time can be complex. Moreover, time delays often separate actions based on a particular understanding of these variables from their outcomes. Short term outcomes can also be different from long term consequences and may even conflict with them. This may prompt managers to tinker with a system without fully understanding the processes and behaviors set in motion by their actions ${ }^{1}$. Feedback loops affect how various parts of a system react to an action, and can cause the final outcome to be greater or weaker than anticipated. Moreover, since feedback loops that amplify and dampen the effects of a particular decision can

\footnotetext{
${ }^{1}$ Deming (1986) provides a detailed discussion on tinkering with systems.
} 
be present simultaneously, it may be difficult to predict how the loops interact and how they impact overall system behavior. Once a decision is made and actions taken, information flows and system behaviors occur at varying rates. Depending on the level of understanding the decision maker has of the dynamics of the system, outcomes may or may not correspond to expectations and may indeed yield counterintuitive results in the both the short and long term. Dynamic complexity can thus create the phenomenon known as 'unintended consequences'.

Dynamic complexity plays a key role in almost every decision made within an organization. Furthermore, the higher the level of the decision, the more likely it is that dynamic complexity will have a major impact on the outcome since higher level decisions typically involve more resources (creating more feedback loops) and are focused on long term objectives (providing greater opportunity for interactions). While it is common for decision makers to experience the impact of unintended consequences, it is not clear whether they are familiar with dynamic complexity or have been adequately trained to deal with it (Senge, 1990). This may be due to the belief that the factors causing dynamic complexity are beyond an individual manager's abilities to deal with, making unintended consequences an unfortunate but unavoidable reality. Research studies have for example shown that human beings have difficulty visualizing behavior over time (Sterman and Booth-Sweeney 2000, Dorner 1996) and in interpreting multiple feedback loops (Forrester 1991). However, others have shown that training can improve a person's ability to deal with dynamic complexity (Cavaleri and Sterman 1997, Maani and Maharaj 2004).

One discipline that seeks to help managers understand and address dynamic complexity is systems thinking (ST). During the last decade of the $20^{\text {th }}$ century several well-respected management experts published books and articles emphasizing that businesses are complex 
social systems and that managers must learn to apply systems thinking skills to be effective in this environment (Senge 1990, Ackoff 1994, Deming 1994, Forrester 1994). This raises the question of where managers should receive this education. Graduate schools of management are a key training ground for future managers. Faculty at these institutions have a responsibility to prepare individuals to lead and to be effective decision makers, and to disseminate new ideas and learning processes. They are where individuals routinely go with the specific objective of developing their decision making capabilities. As such, schools of management have an opportunity to influence management training. This paper assesses whether schools of management are fulfilling this role. This is accomplished by presenting findings of a survey into the current state of ST education at the leading graduate schools of management in the U.S. The survey examines not only how faculty view ST, but what role they believe ST has in a graduate management education and how it is being included in the curriculum. We introduce the survey by first providing a description of the underlying dimensions of ST, and illustrating how specifically the lack of ST awareness contributes to poor decision making.

\section{Cognitive processes involved in systems thinking}

It is inherently difficult to describe ST because it comprises multiple cognitive processes and skill sets. However, for managers to learn to think systemically, these processes must be made explicit. Only then can managers understand the requirements of ST and learn methods that help them develop the corresponding skill set. We therefore propose a multi dimensional description of ST based on the writings of several noted experts in systems theory. The best known element of ST is holistic/synthetic thinking, which Ackoff (1981) differentiated from the

more common analytic thinking. Analytic thinking attempts to understand a system by breaking it into smaller parts and studying the parts in isolation. Once the parts are understood, the 
behavior of the system can be explained based on the behavior of the parts. In contrast, synthetic thinking focuses on understanding the larger context within which the system operates, and based on this, explaining the behavior of the system. While analytic thinking helps people understand $\boldsymbol{w h} \boldsymbol{h}$ t the parts do and how they work, synthetic thinking explains $\boldsymbol{w h} \boldsymbol{y}$ the parts do what they do.

Managers underestimate the importance of understanding what motivates system behavior (Ackoff and Gharajedaghi, 1996). This may be due to their inaccurately recognizing the type of system they are dealing with. Examining how the systems view of the firm has evolved helps one understand how this can occur ${ }^{2}$. For decades, businesses were viewed as mechanistic systems, with non-thinking parts that performed as expected. This view prompted the scientific management movement that was credited with improving manufacturing operations in the early $20^{\text {th }}$ century. Analytic thinking prevailed, the focus being on improving the efficiency of individual work elements. Over time, the systems view shifted to a biological perspective. This corresponded with business owners using equity financing to fund the growth of their organizations. As ownership of the business diffused, managers, rather than owners, became responsible for running organizations. A hierarchy was developed to delineate management and worker activities. Managers were the 'brain' of the organization charged with decision making and problem solving. Workers in contrast were the 'body' of the organization, responsible for carrying out underlying work. In addition, a divisional structure based on specific functions (i.e. finance, operations, etc.) was created to enable the various functions to grow with the business. Analytic thinking still persisted, the prevailing wisdom being that a business would perform optimally if each function optimized its performance in isolation of other functions. This hierarchical/divisional structure, first developed in the first half of the $20^{\text {th }}$

\footnotetext{
${ }^{2}$ Gharajedaghi (1999) provides an excellent in depth discussion of the evolution of the systems view of a business.
} 
century, remains the dominant organizational structure within business organizations today. It is also reflected in how schools of business are typically organized and deliver their curricula.

Deficiencies in the biological view of systems combined with limitations of analytic thinking became apparent as businesses continued to evolve. As each functional area pursued excellence in isolation, conflicts between them began to emerge. Shortages of shared resources and inconsistencies between functional objectives and performance measures were just a few of the causes of these conflicts. Furthermore, social changes forced managers to become aware of other stakeholders in their business. This resulted in a shift to a social systems view of business. Managing social systems is more complex than managing mechanical or biological systems since they are composed of subsystems (e.g. departments, work teams etc.) each of which has its own motivations and objectives. In addition, the subsystems are composed of parts (e.g., employees) with their own unique identities. Moreover, not only must the system contend with internal interactions, there are systems external to the business (i.e. customers, suppliers, special interest groups, etc.) attempting to impose their will and objectives on the organization. It is the ongoing interaction of the objectives and performance of these systems and parts that creates dynamic complexity.

Ackoff and Gharajedaghi (1996) assert that many of the problems observed in business and other social systems are due in part to managing social systems as if they were mechanical or biological. If the various objectives of businesses, their subsystems, and their parts, are not recognized and managed properly, organizations will experience, among other problems, high employee turnover and functional infighting. To effectively manage a multi-minded, multipurpose social system, managers must understand the motivation underlying the behavior of the various elements of the system. Understanding why the parts of the system behave as they do 
enables managers to acknowledge the concerns of the subsystems. By acknowledging these concerns and communicating why they take specific actions, managers reduce the fears of constituents that their interests are being overlooked or dismissed. In summary, managers should take a holistic approach to understanding situations, communicating how and why they are prioritizing objectives, and demonstrating that the concerns of all stakeholders are being considered. We therefore consider synthetic or holistic thinking to be one element of ST.

While holistic thinking is an essential part of ST, it does not sufficiently describe all the cognitive processes necessary to think systemically. Forrester (1971) identified several characteristics of complex systems which make it difficult for people to understand and work with them. These include:

- Cause and effect are often separated both in terms of time and space.

- Actions that improve a situation in the short term often create larger problems in the long term, and actions that make things worse in the short term often have positive long-term effects.

- Due to the first two characteristics, people often do not learn from their mistakes.

- Long time delays often result in one person creating a cause and another experiencing its effect.

- Due to differences between short and long term effects, what a person learns from the short-term result of a decision may differ from the long-term outcome.

- Subsystems and parts of a system interact using multiple, nonlinear feedback loops. The complex flow of interactions often creates counterintuitive behavior. Consequently, what appears to be the right decision may turn out to be a poor one.

Note that the factors identified by Forrester are the key components of dynamic complexity.

Despite social systems exhibiting high levels of dynamic complexity, the tendency is to act in a manner consistent with the awareness of detail complexity alone (Senge, 1990). There are several reasons for this. As children, we typically learn cause and effect thinking through simple events; if I touch a hot stove I get burned, if I do not watch where I am walking I will 
stumble and fall. In addition, the emphasis on analytic thinking throughout the formal education system further reinforces a linear view of cause and effect. Absent the awareness and tools to develop a systemic understanding of cause and effect, individuals naturally develop an eventoriented view of the world (Senge 1990, Sterman 2000). As a result, they view the world as a series of simple cause and effect relationships in which an effect has a single cause that occurred shortly prior to the effect surfacing. This prompts individuals, and in particular, managers, to treat problems as isolated events and to solve them using a discrete, linear process: recognize the problem, identify alternatives, select and implement a solution, resolve the problem. While this may work with simple systems, it is overly simplistic when dealing with complex social systems. The weakness of event-oriented thinking is succinctly articulated by the statement "Today's problems come from yesterday's solutions" (Senge, 1990).

To capture the essence of the arguments of Senge and Forester, we include in the description of ST the concepts of Dynamic Thinking and Closed-Loop Thinking (Richmond, 2000). Dynamic thinking describes the ability to view a phenomenon as the result of behavior over time rather than a reaction to an isolated event. Closed-Loop Thinking reflects the examination of the role that the structure of a system (i.e. performance measures, reward systems, information flows) plays in motivating behavior, and is consistent with the principles of policy deployment and strategic planning. It also examines interactions with external forces. Closed loop thinking focuses on understanding how interactions feed back to shape the result of an intervention.

Synthesizing the above discussion, we propose that ST consists of:

- Synthetic Thinking: studying the role and purpose of a system and its parts to understand why they behave as they do.

- Dynamic Thinking: examining how the system and its parts behave over time. 
- Closed-Loop Thinking: investigating how the parts of a system react and interact to each other and external factors.

\section{Failed decisions and opportunities for systems thinking}

One need not look far to understand the importance of ST to business decision making and by extension to how business leaders are trained. For example, since the early 80's many companies have made large investments of time, money and other resources to implement improvement programs such as lean manufacturing, total quality management, and six sigma. The empirical evidence however suggests that most of these efforts yield disappointing results (Greene, 1993). Common explanations for this are typically a specific event such as a lack of top management support, inadequate training, or selecting the wrong initial project. They also include the failure to develop the infrastructure - people, measurement systems, culture - needed to align actions with goals. These factors however do not account for situations where implementations were initially successful but could not be sustained. In fact, organizations that undertake improvement programs, routinely point to pockets of success. Consequently, the disappointing results described are referring not to an initial implementation failure, but to the inability to sustain the success and make it more widespread. Gharajedaghi (1999) explains that as parts of an organization improve in isolation, they reach a point where they become so interdependent that isolated improvements in one area cause problems in another. These tradeoffs not only prevent overall system improvements they create situations which threaten the very existence of the improvement program. Keating et al., (1999) described an automobile manufacturer that implemented a quality improvement program on the shop floor of one of its plants. The program was initially successful, resulting in the creation of excess capacity in manufacturing. To prevent discouraging further improvement, the organization wanted to avoid 
downsizing and made a commitment to increase sales by developing new vehicles. Existing design processes however were slow, so the manager that implemented the quality improvement program in manufacturing was assigned to oversee implementation of a similar program in $R \& D$. Employees in R\&D however now had two potentially conflicting objectives; increase the number of new car designs, and participate in improvement projects. Not surprisingly, the multiple directives resulted in failure on both fronts. The improvement program never caught on and the number of new cars developed did not increase. Demand did not increase as anticipated thus excess capacity in manufacturing had to be trimmed. As a result, manufacturing personnel became cynical and distrustful of management and the improvement program there died as well.

While it is easy to explain these failures as a failure of management and leadership, this oversimplifies the complexity of the scenario and illustrates the need to take a systemic view of the pattern of events leading to the failure. In particular, failure to understand the impact of the $R$ $\&$ D improvement program on the rate of new product development, coupled with the single minded focus on new product offerings to increase sales volume, led to a cycle of behavior over time that might have been avoided had the potential implications of individual decisions been considered in advance.

Another example of a failure to think systemically occurs when a company uses price incentives or gifts to attract customers rather than through product innovation or developing superior supply chain relationships. Initially, the inducement may increase sales, suggesting that tactic is successful. However, competitors eventually duplicate the incentive making it standard practice rather than a source of unique competitive advantage. In the 1990's this played out in the check printing industry with companies offering first time buyers low prices. Eventually all check printing companies adopted the practice with the result that customers would switch from 
one company to another whenever they needed to place a new order. A similar form of this phenomenon plays out annually in the automotive industry with cash rebates, low interest financing, and other inducements being offered to stimulate sales. The current cycle began with General Motors offering employee pricing to all customers buying 2005 vehicles. Predictably, all U.S. auto makers eventually copied this incentive, the net result being to advance the timing of sales, and to potentially compromise sales of 2006 model cars unless a new incentive is offered. Moreover, the behavior creates the illusion of successful sales without adding value to the underlying product. This not only makes it difficult if not impossible to sustain future sales growth, it removes the incentive to focus on improvement.

These are just two examples of how a failure to think systemically creates self defeating cycles. Other examples can be observed related to downsizing and other cost cutting measures (e.g., cutting R \& D investment in response to a financial crisis with the result that future product development and growth is compromised), the management of constrained resources (e.g., over extending equipment at the expense of maintenance, leading to increased machine failure rates and lower quality/productivity), and the management of rapid growth, amongst others. While all of these situations are discussed extensively in the business literature, it is rare that a systemic perspective is taken. When it is, event oriented solutions are typically offered rather than applying systems thinking principles to develop long-term solutions. This raises the question why aren't systems thinking tools and solutions more prevalent when systemic problems are so common? One explanation is simply that they are not taught. Managers cannot use a tool if they have no knowledge of it. If this is the explanation, it raises the questions of why such tools are not taught and what can be done to address this seemingly critical weakness in the education of managers. To the extent that graduate programs in management are a staple element in the 
education and training of managers, they would appear to be a logical place to, at a minimum, introduce students to the principles and tools of systems thinking. Whether this is in fact the case however, is unclear.

\section{Research objectives}

Our objective was to provide an assessment of the state of ST education in graduate schools of management in the U.S. Understanding how faculty view the role of time, feedback, and interaction in business systems, and how they leverage tools and concepts designed to draw out their effects, has two purposes. First, it represents a starting point in identifying whether schools of management have a role to play in assisting in the training of managers to deal with complexity. Second, it offers insight into what might be done to facilitate any such efforts. Three specific questions were of interest:

- Do faculty understand what ST is?

- Do faculty believe ST has a place in graduate management education?

- Is ST being taught in graduate management programs, and if so, how?

To accomplish our objective, a survey was conducted of faculty at the leading graduate business schools in the U.S. The survey was distributed electronically ${ }^{3}$ to 3,141 faculty members at the top 63 graduate schools of management ${ }^{4}$ To obtain a representative data set, proportionate stratified sampling was used based on faculty disciplines as identified from school websites. Respondents were also asked to report their actual area of expertise. Two hundred and eighteen emails were returned undelivered, the remaining 2,922 yielding 297 useable responses, a response rate of just over $10 \%$. One response came from a faculty member whose discipline was

\footnotetext{
${ }^{3}$ An e-mail was sent describing the study, soliciting responses, and directing respondents to the web site containing the survey instrument. Consistent with standard survey protocol (Dillman, 1999), respondents were sent an e-mail reminder two weeks later, and a second e-mail with instructions for completing the survey two weeks thereafter.

${ }^{4}$ Rankings from five sources were used to identify the top 50 business schools in the U.S.: Business Week, the Wall Street Journal, U.S. News and World Report, the Financial Times, and the Consus Group. As a result, a total of sixty three schools were identified.
} 
outside business and was thus omitted from subsequent analysis. One third of responses came from assistant professors, 18\% from associate professors, and 37\% from full professors. Full time faculty members accounted for $92 \%$ of respondents. All business disciplines were represented within the respondent pool (Table 1). Responses were evenly distributed across disciplines with the exception of operations research and information systems. The small number of responses from these disciplines is however attributable to relatively fewer faculty members in these disciplines rather than to a low response rate. Response rates across disciplines were largely similar.

\begin{tabular}{lcc}
\hline Discipline & Frequency & Percent \\
\hline Operations Management/Supply Chain Management/Logistics (OM) & 47 & 15.9 \\
Accounting (AC) & 45 & 15.2 \\
Finance (FI) & 42 & 14.2 \\
Marketing (MK) & 42 & 14.2 \\
Human Resource Management/Org. Behavior/Industrial Relations (HR) & 32 & 10.8 \\
Strategy/Management/International Business/Entrepreneurship (ST) & 32 & 10.8 \\
Economics (EC) & 25 & 8.4 \\
Operations Research/Decision Sciences/Statistics (OR) & 16 & 5.4 \\
Information Systems (IS) & 9 & 3.0 \\
Other & 6 & 2.0 \\
\hline
\end{tabular}

Table 1. Distribution of Responses by Discipline

\section{Faculty understanding of systems thinking}

Respondents were provided five definitions of ST and asked to select the one they felt best described the concept ${ }^{5}$. They also had the option of supplying their own definition or supplementing/combining any of the definitions provided. Since the purpose of the question was to ascertain how respondents defined ST, it was important that no obvious best answer be provided. Consequently, while one definition was more complete, none incorporated all elements of ST. The specific question and definitions were:

${ }^{5}$ Definitions were developed based on discussions with faculty from different business disciplines at the authors' institution. 
Which of the following best describes how you would define ST?

1. Eliciting inputs from multiple disciplines \& perspectives to develop a more complete understanding of a situation.

2. Identifying the optimal combination and arrangement of resources needed to achieve a desired outcome.

3. Studying how the different parts of an organization interact to achieve a desired outcome.

4. Mapping work flows to determine how information $\%$ material cut across an organization to create value.

5. Understanding how different parts of an organization interact, react to changes over time, and send feedback to affect performance.

6. All of the above

7. Other

The first definition incorporates a holistic approach to decision making by soliciting multiple inputs. However, it does not address complex interactions or feedback loops, both of which are easily overlooked even when seeking multiple inputs. In addition, it does not consider time delays. The second definition represents the classic operations research view of system optimization, and is valuable when dealing with mechanistic systems where the parts behave in highly predictable ways. However it loses relevance when applied to complex social systems with nonlinear feedback and is thus inadequate for most managerial situations (Ackoff 1979). The third definition explicitly addresses interactions between system parts. While it thus addresses one key aspect of ST, it too omits consideration of feedback or time delays. The fourth definition, drawn from the field of process improvement, again reflects a holistic perspective and recognizes interactions within and external to the system of interest. However, it too omits the time dimension. The fifth definition is the most complete, incorporating both feedback loops and behavior over time. One weakness however is its omission of interactions with, and feedback from, external forces. Nevertheless selecting it over other definitions suggests that a respondent has a fairly complete understanding of ST. 
Thirty eight percent of respondents defined ST in a manner that embraces all three of its key elements, interaction, time delay, and feedback (Table 2, definitions 5, 6). This figure varied by discipline. Of faculty in accounting, information systems, operations management, and strategy, $40 \%$ defined ST in a complete manner ${ }^{6}$. In contrast, only $26 \%$ or fewer of faculty in economics, finance, human resource management, and operations research did so. The fact that overall, fewer than $40 \%$ of respondents selected a definition that incorporates all aspects of ST suggests a lack of comprehensive understanding of ST. A small majority (55\%) of all respondents did capture the essence of having a broad view of the organization or problem (Table 2 definitions $1,3,1 / 3,3^{*}$ ) without addressing the dimensions of time or feedback. While a broad view is consistent with a systems view, it overlooks the critical aspect of dynamic thinking that examines system behavior over time. Defining ST more narrowly does not necessarily mean that respondents did not consider these other dimensions. However the fact that definition 5 explicitly included them does suggest a less than complete understanding of ST. Six percent of respondents indicated they had never heard of ST and thus could not define it. Several offered comments that highlighted their indifference, even disdain, for the concept! The implication of these results is that the challenges inherent in increasing coverage of ST in graduate management programs go beyond enlightening faculty unfamiliar with the concept. It involves raising awareness amongst them that they may be teaching students about systems not ST, or that they are providing students with only partial exposure to ST, omitting aspects of time delays and/or feedback loops. Given the impact of these factors on system behavior and a manager's inability to understand how their actions play out, it would seem to be a major omission in graduate management education.

\footnotetext{
${ }^{6}$ It should be noted that disciplines where there appears to be a better understanding of ST appear to be either those which inherently rely on a multidisciplinary, long term approach to decision making (strategy and operations management), or that have a strong information processing dimension (accounting and information systems).
} 


\begin{tabular}{lccccccccc}
\hline \multicolumn{1}{c}{ Definition } & $\begin{array}{c}1 \\
(\mathrm{n}=47)\end{array}$ & $\begin{array}{c}2 \\
\text { Discipline }\end{array}$ & $\begin{array}{c}3 \\
(55)\end{array}$ & $\begin{array}{c}3^{*} \\
(4)\end{array}$ & $\begin{array}{c}1 / 3 \\
(2)\end{array}$ & $\begin{array}{c}4 \\
(20)\end{array}$ & $\begin{array}{c}5 \\
(105)\end{array}$ & $\begin{array}{c}6 \\
(7)\end{array}$ & $\begin{array}{c}8 \\
(18)\end{array}$ \\
\hline AC (n=45) & 20.0 & 8.9 & 17.8 & 0.0 & 2.2 & 2.2 & 42.2 & 0.0 & 6.7 \\
EC (25) & 4.0 & 36.0 & 4.0 & 8.0 & 0.0 & 0.0 & 24.0 & 0.0 & 20.0 \\
FI (42) & 16.7 & 14.3 & 16.7 & 0.0 & 0.0 & 11.9 & 26.2 & 0.0 & 14.3 \\
HR (32) & 9.4 & 6.3 & 15.6 & 3.11 & 50.0 & 6.3 & 16 & 3.1 & 6.3 \\
IS (9) & 33.3 & 0.0 & 0.0 & 0.0 & 0.0 & 11.1 & 44.4 & 11.1 & 0.0 \\
MK (42) & 11.9 & 11.9 & 31.0 & 0.0 & 2.4 & 9.5 & 26.2 & 4.8 & 2.4 \\
OM (47) & 12.8 & 8.5 & 25.5 & 2.1 & 0.0 & 4.3 & 44.7 & 2.1 & 0.0 \\
OR (16) & 18.8 & 12.5 & 37.5 & 0.0 & 0.0 & 12.5 & 18.8 & 0.0 & 0.0 \\
ST (32) & 28.1 & 12.5 & 3.1 & 0.0 & 0.0 & 9.4 & 37.5 & 6.3 & 3.1 \\
Other (6) & 16.7 & 16.7 & 33.3 & 0.0 & 0.0 & 0.0 & 33.3 & 0.0 & 0.0 \\
\hline Overall & 15.9 & 12.5 & 18.6 & 13.6 & 6.8 & 6.8 & 35.6 & 2.4 & 6.1 \\
\hline
\end{tabular}

N.B. Results expressed as \% within discipline

Key: 1. Eliciting inputs from multiple disciplines \& perspectives to develop a more complete understanding of a situation

2. Identifying the optimal combination and arrangement of resources needed to achieve a desired outcome

3. Studying how the different parts of an organization interact to achieve a desired outcome

1/3. Respondent provided definition combining 1 and 3

$3^{*}$. Respondent provided definition based on 3

4. Mapping work flows to determine how information \& material cut across an organization to create value

5. Understanding how different parts of an organization interact, react to change over time, and send feedback, to affect performance.

6. Respondent provided definition embracing 1-5

8. Unfamiliar with term

Table 2. Definitions of ST by Discipline

\section{Systems thinking in the curriculum - perceptions}

Respondents were asked whether ST should be an integral part of a graduate management program. Despite the disparity in how faculty defined ST, 78\%, agreed or strongly agreed that ST was an essential part of a graduate management program ${ }^{7}$ (Table 3). In contrast, only $5 \%$ disagreed or strongly disagreed. However, the data also reveal some disturbing results. Of respondents who selected definition 3 (including only the interaction element), $30 \%$ were either unsure of its importance in graduate management programs or disagreed that it is essential. This is both surprising and of cause for concern. That faculty would question even the need to emphasize interactions within a system suggests that some may see the world narrowly through

\footnotetext{
${ }^{7}$ Percentages varied from below $65 \%$ (economics, finance) to above $85 \%$ (operations management, information systems, strategy). In other words, with the exception of faculty in accounting, a loose positive relationship between how broadly ST is defined and how important ST is perceived to be can be observed.
} 
the lens only of their field and background. It also suggests for some, there may be a desire or willingness to oversimplify problems to fit an existing paradigm, pedagogy, or teaching style they are comfortable with. For this to come from faculty at the leading business schools is only more intriguing. Of similar concern is that $20 \%$ of faculty appear to have a more comprehensive view of ST (i.e. Table 2, definitions 5, 6) but are either unsure of its importance or believe it is unimportant. While the expectation was that faculty who recognize the richness of ST would readily embrace it, it is apparent that several do not believe that it is essential. There are several possible reasons for this. Some faculty may not believe that ST can be taught or that students should receive this part of their education elsewhere. They may believe that there are other more pressing needs in the curriculum. The lack of appropriate incentives, both related to compensation as well as promotion and tenure decisions, may also be a factor. It is also possible that faculty may not want to make the adjustments in curriculum or pedagogy to encompass ST. Unfortunately the survey does not allow detailed analysis of the underlying reasoning to be made. Whatever the reason, the results suggest not only that opportunities exist to increase student awareness and knowledge of ST but that work is needed to educate faculty about what it is and its importance to teaching decision making.

\begin{tabular}{lccccc}
\hline Importance & $\begin{array}{c}\text { Strongly } \\
\text { Agree }\end{array}$ & Agree & Unsure & Disagree & $\begin{array}{c}\text { Strongly } \\
\text { Disagree }\end{array}$ \\
\hline $1(\mathrm{n}=47)$ & 51.1 & 38.3 & 10.6 & 0.0 & 0.0 \\
$2(37)$ & 27.0 & 40.5 & 27.0 & 2.7 & 2.7 \\
$3(55)$ & 23.6 & 47.3 & 23.6 & 5.5 & 0.0 \\
$3^{*}(4)$ & 75.0 & 25.0 & 0.0 & 0.0 & 0.0 \\
$1 / 3(2)$ & 100.0 & 0.0 & 0.0 & 0.0 & 0.0 \\
$4(20)$ & 20.0 & 60.0 & 15.0 & 5.0 & 0.0 \\
$5(105)$ & 38.1 & 40.9 & 15.2 & 3.8 & 1.0 \\
$6(7)$ & 42.9 & 42.9 & 0.0 & 0.0 & 14.3 \\
\hline Overall & 35.6 & 42.4 & 16.9 & 3.2 & 1.1 \\
\hline N.B. Results expressed as \% within discipline & & & \\
^Adjusted for respondents with no understanding of the term ST & & &
\end{tabular}

Table 3. Importance of ST in Program by Definition 
Of the 89 responses to define ST broadly (Table 2, definitions 5, 6) and that it is an essential part of a graduate management program, 70\% went further, agreeing or strongly agreeing with a question asking whether ST should be part of every class in a graduate management program. This suggests that a majority of faculty that define ST broadly and consider it an essential element of a graduate management education view it not only as an approach to decision making and problem solving that transcends all aspects of a graduate management education, but that its concepts should be reinforced across the curriculum. It also suggests that if awareness among faculty of the scope of ST can be increased, recognition of its value to and importance in graduate management education will increase. Results also suggest that faculty in disciplines that inherently lend themselves to an inter-disciplinary view of problems (i.e., strategy, operations management), or who, through information processing, see the whole as opposed to just parts (i.e., accounting, information systems), have a clearer understanding of the value of ST than those with a more piecemeal perspective.

Whether or not they believe ST is crucial in their own discipline, faculty from all disciplines believe the impact of interaction, feedback, and time delay should be covered in the curriculum (Table 4). Furthermore, most feel that disciplines that inherently employ an interdisciplinary view of problems (i.e. operations management and strategy) are a natural home of ST within the curriculum. Between 50 and $60 \%$ of respondents also indicated that ST had a role in the human resource management, information systems, and operations research curricula. It is interesting to note that $40 \%$ or fewer of faculty felt that ST should be covered in accounting, marketing, economics, or finance courses. This suggests an opportunity to make stronger connections between ST and these fields. For example, the Growth and Underinvestment 
system archetype, a classic model of behavior in complex systems within the ST community, can be used to explain the well known finance problem of growth and financing.

\begin{tabular}{llllllllll}
\hline Discipline & ST & \multirow{2}{*}{ OM } & OR & IS & HR & AC & MK & EC & FIN \\
\hline AC & 84.2 & 84.2 & 63.2 & 84.2 & 47.4 & 73.7 & 21.1 & 15.8 & 21.1 \\
EC & 83.3 & 33.3 & 50.0 & 33.3 & 50.0 & 16.7 & 16.7 & 66.7 & 16.7 \\
FIN & 81.8 & 45.5 & 63.6 & 36.4 & 36.4 & 36.4 & 27.3 & 18.2 & 36.4 \\
HR & 70.6 & 82.4 & 76.5 & 47.1 & 64.7 & 29.4 & 29.4 & 29.4 & 29.4 \\
IS & 80.0 & 80.0 & 80.0 & 80.0 & 60.0 & 60.0 & 60.0 & 60.0 & 40.0 \\
MK & 69.2 & 69.2 & 69.2 & 61.5 & 53.8 & 23.1 & 46.2 & 23.1 & 38.5 \\
OM & 63.6 & 81.8 & 40.9 & 54.5 & 50.0 & 31.8 & 36.4 & 18.2 & 27.3 \\
OR & 66.7 & 100 & 33.3 & 33.3 & 66.7 & 33.3 & 33.3 & 66.7 & 33.3 \\
ST & 100 & 73.3 & 60.0 & 60.0 & 66.7 & 33.3 & 33.3 & 60.0 & 26.7 \\
\hline Overall & 77.5 & 73.9 & 60.4 & 57.7 & 54.1 & 38.7 & 32.4 & 31.5 & 28.8 \\
\hline
\end{tabular}

N.B. Results expressed as \% within discipline

Table 4. Relevance of ST in Program by Discipline

\section{Developing systems thinking skills}

Before addressing what can be done to educate faculty and students about ST, it is helpful to first understand why decision makers tend not to think systemically. As described earlier, people generally have an event-oriented view of the world. Possible reasons for this include prior education, a focus on action rather than investigation, and time pressure to make a decision. Empirical research has also demonstrated the difficulty of individuals in conceptualizing and managing dynamic complexity (Booth Sweeney and Sterman 2000, Dorner 1996). Furthermore, these studies showed that this difficulty transcends age, national origin, educational background, and other demographic variables. It appears that the ability to think systemically is not innate for most humans but must be developed. Absent such training, it is not surprising that individuals, faced with complexity, simplify problems or rationalize away complexity, with the consequences described earlier. This raises the question of how to teach someone to think systemically. While we cannot teach someone how to think, we can teach tools and concepts that focus thinking 
processes in a particular way. For example, the scientific method does not teach analytic thinking but offers a tool set that helps researchers isolate variables and study their impact on a phenomenon of interest. Over the years virtually every field has developed its own set of analytical thinking tools. By analogy, while systems thinking cannot be taught, the tools of systems thinking can be used to help people think systemically.

Several tools have been developed to facilitate an understanding of how parts of a system interact. For example, Value Stream Mapping was developed within the lean manufacturing community to trace workflows and differentiate value adding from non-value adding activities. In the field of Accounting, the Balanced Scorecard was developed to help managers simultaneously assess the performance of a business across multiple dimensions. Policy Deployment, a tool of strategic management, facilitates an understanding of how various initiatives can be deployed horizontally and vertically within an organization. While these are important tools that help managers think holistically, they do not address feedback loops or behavior over time. To accomplish this requires the use of tools such as Causal Loop Diagrams, System Archetypes, and Stock and Flow Maps.

Causal Loop Diagrams (CLD) illustrate feedback structures within a system (Sterman 2000b) and are useful for communicating the mental models individuals or teams have about how actions feed back through a system. As individuals learn to develop CLDs, they are better able to organize and articulate their understanding about system behavior, as well as develop a richer appreciation of the true dynamics of the system. Moreover, the development of CLD's helps individuals avoid the oversimplification that typically occurs when attempting to explain complex system behavior. System Archetypes, based on CLD's, are generic structures that represent specific combinations of feedback loops that occur in a wide variety of complex 
systems (Senge 1990). Once one is aware of the archetypes, it is often possible to recognize them within a particular system, to use them to explain counterintuitive outcomes, and to identify leverage points for improving system performance. Central to the understanding of dynamic system behavior is that items move through the system and accumulate at various points. Stock and Flow Maps can be used to diagram this aspect of system behavior. In addition to helping people visualize how the structure of a system explains behavior, these maps are the primary tool for building dynamic simulation models to demonstrate how a system might behave over time.

The tools described above are designed to help people thinking systemically ${ }^{8}$. They are not specific to a particular business function nor do they require a particular educational or professional background to be understood. As such they can be applied to a variety of scenarios to provide insight into behavior in a systemic way. Moreover, they enable managers to better understand the systems they work within and to communicate this understanding to others without oversimplification. Of relevance to this study is whether these tools are in fact being used to teach ST, and if not, what tools are being used.

\section{Systems thinking in the curriculum - practice}

Faculty were probed about how ST was taught at their institution and in particular within their discipline. This analysis focuses on the 112 respondents that indicated a more complete definition of ST (Table 2, definitions 5, 6). Only those with a complete understanding of ST can be expected to offer accurate insights regarding its coverage in the curriculum. Fifty respondents (45\%) indicated that ST was taught in their school's graduate management program, $60 \%$ of whom agreed or strongly agreed that their program did an adequate job teaching ST. A further 19 respondents indicated they were not sure if ST was being taught or not. While these results

\footnotetext{
${ }^{8}$ Sterman (2000) provides a detailed description of these tools.
} 
might suggest that ST is becoming a part of graduate management education, they also indicate that it has yet to become common place even at leading programs let alone across the spectrum of graduate programs. However, putting these numbers in perspective highlights the scope to increase and improve how graduate management students are exposed to ST. First, the 50 respondents may have included multiple responses from the same institution, reducing the number of institutions at which ST is being taught. Second, only 27\% (30/112) of respondents who appear to have a broad understanding of what ST is, say it is being taught adequately. Third, only 14\% (30/216) of respondents who indicated that ST should be an integral part of management education, regardless of how they define ST, say likewise.

Survey respondents were presented with discipline specific lists of tools that might be used to present ST concepts ${ }^{9}$ (Table 5). Lists were composed primarily of tools and concepts that help decision makers take a holistic perspective of systems (e.g., Value Stream Mapping, Balanced Score Card). In addition, each list included tools designed specifically to aid understanding of the impact of feedback loops and time delays on system behavior (e.g., causal loop diagrams, stock \& flow maps). Respondents were also given the option to list other tools.

From the results of the 36 respondents who defined ST broadly and indicated that ST was taught in their discipline, it is apparent that while a variety of tools/concepts are being used, few faculty use tools that address elements of time delay and feedback. The most commonly taught tools/concepts are those designed to view problems or decision making scenarios from a multidimensional/disciplinary perspective without addressing the impact of time delays or feedback (e.g., balanced scorecard, fishbone diagrams). In contrast, there is little evidence that causal loop diagrams and stock and flow maps are being taught. This is despite the fact that responses came

\footnotetext{
${ }^{9}$ Lists of tools/concepts relating to systems that are typically found in courses in specific disciplines were composed from discussions with faculty in each discipline area.
} 


\begin{tabular}{|c|c|c|c|c|c|c|c|}
\hline Tool/Concept $^{\wedge} \quad$ Discipline $^{*}$ & $\begin{array}{c}\mathrm{AC} \\
(\mathrm{n}=8)\end{array}$ & $\begin{array}{l}\text { FI } \\
(3)\end{array}$ & $\begin{array}{r}\mathrm{HR} \\
(7)\end{array}$ & $\begin{array}{l}\text { IS } \\
(2)\end{array}$ & $\begin{array}{c}\text { MK } \\
(3)\end{array}$ & $\begin{array}{c}\mathrm{OM} \\
(6)\end{array}$ & $\begin{array}{l}\text { ST } \\
(4)\end{array}$ \\
\hline Causal Loop Diagrams & 1 & 1 & 2 & 1 & 0 & 1 & 2 \\
\hline Stock and Flow Diagrams & 1 & 1 & 0 & 0 & 0 & 3 & 1 \\
\hline Balanced Scorecard & 7 & & & & & & \\
\hline Data Flow Diagrams & 4 & & & 0 & & & \\
\hline Enterprise Resource Planning & 3 & & & & & & \\
\hline Entity Relationship Diagrams & 4 & & & 0 & & & \\
\hline Flowcharts/Process Maps & 5 & & & & & & \\
\hline Associative Databases & 2 & & & & & & \\
\hline Banking Systems & & 1 & & & & & \\
\hline Foreign Exchange & & 1 & & & & & \\
\hline Government Monetary Systems & & 1 & & & & & \\
\hline International Financial Systems & & 1 & & & & & \\
\hline Money Markets & & 1 & & & & & \\
\hline Equifinality & & & 4 & & & & 0 \\
\hline Policy Deployment/Hoshin Planning & & & 1 & & & & 1 \\
\hline Strategic Planning & & & 4 & & & & 2 \\
\hline Team Building & & & 6 & & & & \\
\hline Rational Flow Diagrams & & & & 0 & & & \\
\hline Systems Development Life Cycle & & & & 0 & & & \\
\hline Unified Modeling Language & & & & 0 & & & \\
\hline Work Breakdown Structure Diagrams & & & & 0 & & & \\
\hline Consumer Behavior Model & & & & & 2 & & \\
\hline Distribution/Logistics Management & & & & & 2 & & \\
\hline Marketing Plan/Audit & & & & & 2 & & \\
\hline Fishbone Diagrams & & & & & & 3 & \\
\hline Lean Production Systems & & & & & & 3 & \\
\hline PDCA/DMAIC Cycle & & & & & & 3 & \\
\hline Quality Function Deployment & & & & & & 1 & \\
\hline Supply Chain Management & & & & & & 3 & \\
\hline Theory of Constraints & & & & & & 3 & \\
\hline Value Stream Mapping & & & & & & 2 & \\
\hline
\end{tabular}

N.B. Results expressed as frequencies $\quad{ }^{*}$ Only disciplines with multiple responses included

$\wedge$ Blank cell indicates tool was not in list for corresponding discipline

Table 5. Application of ST

from faculty that indicated they understood that ST encompasses interactions, time delays, and feedback. What this suggests is that tools associated only with detail complexity and not dynamic complexity are being taught. It is possible that faculty do in fact address time delays and feedback without using ST tools or that they use the tools without knowing them by name. 
However, even allowing for this, it appears that while faculty are at least implicitly raising awareness of ST, only a few are teaching all aspects of it.

Further evidence of a disconnect between faculty intent and practice comes from the fact that while only 12 faculty who defined ST broadly stated that ST tools were taught within their disciplines, of the entire sample $(n=296), 35$ faculty said they used them ${ }^{10}$. Furthermore, the majority of faculty who indicated ST tools were being taught within their disciplines defined ST in a manner that encompassed only the interaction dimension of ST. This suggests one of two things. First, faculty, due perhaps to their limited understanding of ST, may be using tools that address only the interaction dimensions of ST. Second, faculty may be using ST tools unaware they are associated with ST and part of a larger tool set. What must be concluded therefore is that not only does a significant gap exist in the understanding of what ST is, but also of what it can accomplish when its tools are fully leveraged.

\section{Opportunities and challenges}

Toward the end of the $20^{\text {th }}$ century, several authors cited the need to view and manage businesses from a social systems perspective. Others predicted a growing need to think systemically and evidence from business supports their predictions. Evidence from the business press provides further support that analytic thinking alone cannot solve the complex problems typical of today's business environment. While not the only one, ST does represent a complementary approach to decision making that should no longer be viewed merely as an interesting concept but as a necessary managerial skill. As such, those responsible for grooming the next generation of managers must incorporate the tools and techniques designed to develop

\footnotetext{
10 This included one faculty member each in operations management and operations research who, while defining ST in terms of interactions, time delays, and feedback, was either unsure whether ST was taught within their discipline (OM), or did not respond to the question on teaching of ST within their discipline (OR).
} 
awareness and practice of ST into their training programs and curricula. If they don't, can we realistically expect better performance from future managers?

Over the last decade, there has been an increase in the teaching of system-oriented topics in virtually every field of business. In addition, many business schools have taken a more crossfunctional, integrative approach to course delivery. Despite these efforts however, criticisms of MBA curricula persist (Ghoshal 2005, Bennis and O'Toole 2005) and curricula continue to evolve (Bisoux 2005). Absent from these efforts has been a comprehensive treatment of ST. While schools are teaching students about systems and detail complexity using the synthetic aspect of systems thinking, they do not appear to be addressing dynamic complexity or applying principles of closed loop or dynamic thinking. While the need remains for a greater understanding of the breadth of ST, the fact is that at least some faculty in all business disciplines are aware of the multiple dimensions of ST and do in fact teach students about them. This illustrates that ST has application across business functions. Moreover, despite the fact that they do not feel ST is adequately covered in their programs, faculty recognize its value and potential in the curriculum. This alone should provide the motivation for business schools to modify and improve their programs by including or extending coverage of ST.

Bringing about change within academia does not come without significant challenge and we would be remiss not to recognize this reality. Faculty have a reputation, whether deserved or not, of being 'independent contractors', focused more on individual agendas than on substantive change that might enhance the learning process. There may well be rational, legitimate reasons why some respondents that appeared to have a fairly comprehensive understanding of ST do not feel it is a necessary element of a graduate management curriculum. While we do not express an opinion on the issue nor do the results enable us to draw a deeper conclusion, they do provide 
possible support for the claims of several authors that business school faculty are less concerned with good pedagogy than they are with maintaining the status quo. Faculty who are motivated to bring about change face the challenge of determining whether there is material they can afford to omit in order to introduce new material. Some may feel unprepared or unqualified to make the shift from an emphasis on content delivery and/or analytic thinking to one that relies on decision making processes and/or ST. Absent support from faculty and administration, they may also be uncomfortable taking the role of change agent. The absence of rewards related to the promotion and tenure process and in facilitating curriculum change may also be a factor. The observation however that the broader the understanding of the breadth of ST, the greater the likelihood that one sees the importance of ST, does suggest that a few vocal advocates for ST can create momentum for change. One also cannot overlook the importance of college administrators in recognizing the value of ST and in their developing internal systems to motivate faculty to include it in the curriculum. As business schools enter the $21^{\text {st }}$ century and contend with how to prepare their students for the increasing complexity they will face as leaders, it is hoped that increased coverage of ST will be part of the solution. However, before this can happen, more must be done to increase awareness among faculty about ST and how it can play a role in redefining management education.

\section{REFERENCES}

Ackoff, R.L. (1979) 'The future of operational research is past', Journal of the Operational Research Society, Vol. 30, 93-104.

Ackoff, R.L. (1981) 'Our changing concept of the world', in Creating the Corporate Future (pp. 3-26), New York: John Wiley and Sons.

Ackoff, R.L. (1994) The Democratic Corporation: A Radical Prescription for Recreating Corporate America and Rediscovering Success. New York: Oxford University Press.

Ackoff, R.L. and Gharajedaghi, J. (1996) 'Reflections on systems and their models', Systems Research, Vol. 13, No. 1, pp. 3-23. 
Bennis, W.G. and O'Toole, J. (2005) 'How business schools lost their way', Harvard Business Review, Vol. 83, No. 5, pp. 96-104.

Bisoux, T. (2005) 'The extreme MBA makeover', BizEd, May/June, pp. 26-33.

Booth Sweeney, L. and Sterman, J.D. (2000) 'Bathtub dynamics: initial results of a systems thinking inventory', System Dynamics Review, Vol. 16, pp. 249-286.

Bossidy, L. and Charan, R. (2002) 'The gap nobody knows', In Execution: The Discipline of Getting Things Done (pp. 13-34), New York: Crown Business.

Cavaleri, S. and Sterman, J.D. (1997) 'Towards evaluation of systems thinking intervention: A case study', System Dynamics Review, Vol. 13, pp. 171-186.

Charan, R. (2005) 'Ending the CEO Succession Crisis', Harvard Business Review, Vol. 83, No. 2, pp. 72-81.

Deming, W.E. (1994) 'Introduction to a System', in The New Economics for Industry, Government, Education (pp. 49-91), Cambridge: MIT Center for Advanced Educational Services.

Deming, W.E. (1986) 'Common causes and special causes of improvement', in Out of the Crisis (pp. 309-370), Cambridge: MIT Center for Advanced Engineering Study.

Dorner, D. (1996) 'Time sequences', in The Logic of Failure: Recognizing and Avoiding Error in Complex Situations (pp. 107-152), Cambridge: Basic Books.

Forrester, J.W. (1971). The counterintuitive behavior of social systems. Technology Review, 73 (3), 52-68.

Forrester, J.W. (1991) 'System dynamics and the lessons of 35 years in the systemic basis of policy making in the 1990s', http://www.sysdyn.clexchange.org/papers/d-4224-4.pdf

Forrester, J.W. (1994) 'Learning through systems dynamics as preparation for the $21^{\text {st }}$ century', Keynote Address for Systems Thinking and Dynamic Modeling Conference for K-12 Education. Concord: Concord Academy.

Gharajedaghi, J. (1999) 'How the game is evolving', in Systems Thinking: Managing Chaos and Complexity (pp. 3-27), Woburn: Butterworth-Heinemann.

Gharajedaghi, J. and Ackoff, R.L. (1984) 'Toward systemic education of systems scientists', Systems Research, Vol. 2, No. 1, pp. 21-27.

Ghoshal, S. (2005) 'Bad management theories are destroying good management practices', Academy of Management Learning and Education, Vol. 4, No. 1, pp. 75-91.

Greene, R. (1993) Global Quality: A Synthesis of the World's Best Management Models. Milwaukee: American Society for Quality Control Press.

Keating, E.K., Oliva, R., Repenning, N.P., Rockart. S. and Sterman, J.D. (1999) 'Overcoming the improvement paradox', European Management Journal, Vol. 17, No. 2, pp. 120-134.

Maani, K.E. and Maharaj, V. (2004) 'Links between systems thinking and complex decision making', System Dynamics Review, Vol. 20, pp. 21-48.

Morris, L. (2003) 'Business model warfare: The strategy of business breakthroughs', http://www.innovationlabs.com/BusModelWarfare.pdf 
Richmond B. (2000) The Thinking in Systems Thinking: Seven Essential Skills. Waltham: Pegasus Communications Inc.

Senge, P.M. (1990) 'Prisoners of the system or prisoners of our own thinking', in The Fifth Discipline: The Art and Practice of the Learning Organization (pp. 27-54), New York: Doubleday/Currency.

Sterman, J.D. (2000a) 'Learning in and about complex systems', in Business Dynamics: Systems Thinking and Modeling for a Complex World (pp. 3-39), Burr Ridge: Irwin-McGraw-Hill.

Sterman, J.D. (2000b) 'Causal loop diagrams', in Business Dynamics: Systems Thinking and Modeling for a Complex World (pp.135-190), Burr Ridge: Irwin-McGraw-Hill. 